\title{
CARDIAC PERFORMANCE AFTER DEEP HYPOTHERMIC CIRCULATORY ARREST IN CHRONICALLY CYANOTIC NEONATAL LAMBS
}

Mitsugi Nagashima, MD

Georg Nollert, $\mathrm{MD}^{\mathrm{a}}$

Ulrich Stock, MDa

Jason Sperling, MD $^{\mathrm{a}}$

Shinichi Hatsuoka, MD

Dominique Shum-Tim, MD

Koh Takeuchi, MD

Arthur Nedder, DVM ${ }^{\mathrm{b}}$

John E. Mayer, Jr, MD
Objectives: It is controversial whether immature cyanotic hearts are more susceptible to ischemic injury than normoxemic hearts. Acutely induced alveolar hypoxic stress before cardiopulmonary bypass has been used as a model of cyanosis and is reported to worsen recovery of immature hearts after subsequent ischemic insult by means of a free radical injury mechanism. Because of concerns about the relevance of acute alveolar repair to the chronic cyanosis encountered clinically, we assessed the effects of chronic cyanosis without alveolar hypoxia, acute alveolar hypoxia, and normoxemia on recovery of cardiac function after deep hypothermic circulatory arrest.

Methods: A chronic cyanosis model was created in 8 lambs by an antomosis between the pulmonary artery and the left atrium (cyanosis group). Eight lambs underwent sham operation (control). One week later, the animals underwent cardiopulmonary bypass with 90 minutes of deep hypothermic circulatory arrest at $18^{\circ} \mathrm{C}$. Another 8 lambs underwent 45 minutes of hypoxic ventilation before bypass, with arterial oxygen tension being maintained at $30 \mathrm{~mm} \mathrm{Hg}$ (acute hypoxia group). Cardiac index, preload recruitable stroke work, and tau were measured. Malondialdehyde and nitrate-nitrite, nitric oxide metabolites, were also measured in the coronary sinus. Myocardial antioxidant reserve capacity at 2 hours of reperfusion was assessed by measuring lipid peroxidation in left ventricular tissue samples incubated with t-butylhydroperoxide at $37^{\circ} \mathrm{C}$.

Results: Oxygen tension was $35 \pm 3 \mathrm{~mm} \mathrm{Hg}$ in the acute hypoxia group versus $93 \pm 7 \mathrm{~mm} \mathrm{Hg}$ in the control group. In the acute hypoxia group the recovery of cardiac index, preload recruitable stroke work, and tau were significantly worse than that found in both the control and cyanosis groups. Preload recruitable stroke work at 2 hours of reperfusion was slightly but significantly lower in the cyanosis group than in the control group. The postischemic level of nitric oxide metabolites was significantly lower in the acute hypoxia group than in the cyanosis and control groups. However, malondialdehyde levels in the coronary sinus and myocardial antioxidant reserve capacity were not significantly different among the groups.

Conclusion: Recovery of left ventricular function after deep hypothermic circulatory arrest in neonatal lambs with chronic cyanosis was slightly worse than that found in acyanotic animals. Acute hypoxia before bypass was associated with significantly worse recovery of left ventricular function, and the mechanism of injury may be related to an impairment of nitric oxide production. Free radical injury does not appear to explain any differences among cyanotic, acyanotic, and acutely hypoxic animals in recovery of left ventricular function after ischemia. (J Thorac Cardiovasc Surg 2000;120:238-46)
From the Department of Cardiovascular Surgery, ${ }^{a}$ Children's Hospital and Harvard Medical School, Animals Resources, ${ }^{\text {b }}$ Children's Hospital and Harvard Medical School, Boston, Mass.

Read at the Seventy-ninth Annual Meeting of The American Association for Thoracic Surgery, New Orleans, La, April 18-21, 1999.

Received for publication April 22, 1999; revisions requested June 11, 1999; revisions received Feb 29, 2000; accepted for publication March 6, 2000.
Address for reprints: John E. Mayer, Jr, MD, Department of Cardiovascular Surgery, Children's Hospital, Harvard Medical School, 300 Longwood Ave, Boston, MA 02115.

Copyright (C) 2000 by The American Association for Thoracic Surgery

$0022-5223 / 2000 \$ 12.00+0 \quad \mathbf{1 2 / 6 / 1 0 6 9 8 4}$

doi:10.1067/mtc.2000.106984 
It remains controversial whether cyanotic hearts are more susceptible to ischemia-reperfusion than normoxemic hearts. Comparisons on the basis of clinical results are difficult because many congenital cyanotic lesions also involve pressure overload, volume overload, or both. In addition, postoperative management with inotropic or afterload-reducing agents complicates the assessment of heart function. It has been reported that chronic alveolar hypoxia increases the tolerance of the neonatal heart to ischemia compared with normoxemia. ${ }^{1,2}$ In contrast, Fujiwara and associates $^{3}$ demonstrated that hearts from neonatal lambs with surgically created cyanosis have slightly worse functional recovery than normoxemic hearts after ischemia when evaluated in an isolated heart model. Several authors report that acute alveolar hypoxic stress before cardiopulmonary bypass (CPB) is associated with severe postischemic cardiac dysfunction, and the mechanism of injury has been attributed to oxygen-derived free radicals. ${ }^{4-6}$ However, it is uncertain that the acute alveolar hypoxia model is relevant to the chronic cyanosis encountered in patients with severe forms of congenital heart disease. The objective of the current study was to assess whether chronic cyanosis without alveolar hypoxia affects the tolerance or susceptibility of neonatal hearts to myocardial ischemia under conditions of deep hypothermic circulatory arrest (DHCA) with CPB. Second, we compared chronic cyanosis with acute hypoxia to evaluate whether acute alveolar hypoxia is an appropriate model as chronic cyanosis.

\section{Methods}

Creation of cyanosis. Sixteen neonatal lambs (age $4.6 \pm$ 0.9 days; weight $4.3 \pm 0.3 \mathrm{~kg}$ [mean $\pm \mathrm{SEM}]$ ) were anesthetized with intramuscular injection of ketamine hydrochloride $(50 \mathrm{mg} / \mathrm{kg})$. After intubation, the anesthesia was maintained by inhalation of isoflurane. A left thoracotomy was performed in the third intercostal space. The ductus arteriosus was ligated with a silk suture after the pericardium was entered. A model of chronic cyanosis was created in 8 of the lambs by an anastomosis between the pulmonary artery (PA) and the left atrium (LA). Two partial side-biting clamps were placed on the left PA and on the LA adjacent to the atrioventricular groove to avoid entering its trabecular portion. The length of the longitudinal incision at the PA was empirically chosen to be the same size as the diameter of the left PA (5-7 $\mathrm{mm})$. The LA was anastomosed to the PA by a continuous 7-0 monofilament suture. A vessel loop was taped around the anastomosis as a marker and to facilitate dissection at the second procedure. The remaining 8 lambs underwent a thoracotomy and a sham operation (control), which was identical except that the PA and the LA were not incised and the anas- tomosis was not carried out. The sham procedure did include 20 minutes of side clamping of the PA and the LA. The animals were given intramuscular injections of antibiotics during the procedures and 12 hours after the procedures, and buprenorphine hydrochrolide $(0.01 \mathrm{mg} / \mathrm{kg})$ was given to minimize discomfort and pain every 8 hours for the first 48 hours after the procedures. The animals survived for 7 days.

DHCA study. The lambs were anesthetized with intramuscular injection of ketamine hydrochloride $(50 \mathrm{mg} / \mathrm{kg})$. After intubation, the animals' lungs were artificially ventilated with a volume-controlled ventilator (Servo Ventilator 900C; Siemens-Elema, Danvers, Mass) with a tidal volume of $20 \mathrm{~mL} / \mathrm{kg}$ and $4 \mathrm{~cm} \mathrm{H} \mathrm{H}_{2} \mathrm{O}$ of positive end-expiratory pressure at an inspired oxygen fraction $\left(\mathrm{FIO}_{2}\right)$ of $100 \%$ during the experiment. After a bolus intravenous infusion of $300 \mu \mathrm{g} / \mathrm{kg}$ fentanyl, anesthesia was maintained by continuous intravenous infusion of ketamine $\left(5 \mathrm{mg} \cdot \mathrm{kg}^{-1} \cdot \mathrm{h}^{-1}\right)$, midazolam $\left(0.2 \mathrm{mg} \cdot \mathrm{kg}^{-1} \cdot \mathrm{h}^{-1}\right)$, pancuronium $\left(\mathrm{mg} \cdot \mathrm{kg}^{-1} \cdot \mathrm{h}^{-1}\right)$, and fentanyl $\left(50 \mu \mathrm{g} \cdot \mathrm{kg}^{-1} \cdot \mathrm{h}^{-1}\right)$ throughout the experiment. A 19gauge catheter was inserted through the left femoral artery and passed into the thoracic aorta for measurements of systemic arterial pressure and for blood gas sampling. Through a median sternotomy, the heart was exposed. A cotton tape was placed around the inferior vena cava (IVC) to allow transient occlusions. A 5F side-holed catheter (Berman angiographic catheter; Arrow International Inc, Reading, Pa) was inserted to measure PA pressure. After systemic heparinization, a $5 \mathrm{~F}$ polyurethane sheath was inserted into the LA for pressure measurement and blood sampling. A 19-gauge catheter was also inserted into the coronary sinus through the hemiazygos vein. A micromanometer catheter (SPC-350; Millar Instruments Inc, Houston, Tex) was placed into the left ventricular (LV) cavity through the apex to measure LV pressure. Two pairs of ultrasonic transducers (Sonometrics, London, Canada) were implanted in the LV midmyocardium to measure the length of the long and short axes. Another 8 lambs (age $4.4 \pm 1.2$ days; weight $3.8 \pm 0.2 \mathrm{~kg}$ [mean \pm SEM]) underwent 45 minutes of hypoxic ventilation before $\mathrm{CPB}$, with arterial oxygen tension $\left(\mathrm{PaO}_{2}\right)$ being maintained at $30 \mathrm{~mm} \mathrm{Hg}$ (acute hypoxia [AH] group) after ligation of the ductus arteriosus and instrumentation (Fig 1). In the cyanosis group the PA-LA shunt was ligated immediately before CPB.

The circuit for CPB consisted of a roller pump and a membrane oxygenator (VPCML; COBE Laboratories, Arvada, Colo). The pump prime consisted of $200 \mathrm{~mL}$ of electrolyte solution (Normosol-R; Abbott Laboratories, North Chicago, Ill) and $500 \mathrm{~mL}$ of homologous heparinized fresh donor blood to achieve a hematocrit level of $20 \%$. An $8 \mathrm{~F}$ arterial cannula and a $24 \mathrm{~F}$ venous cannula were placed into the right femoral artery and right atrium, respectively. The animals were cooled to $18^{\circ} \mathrm{C}$ over 30 minutes by $\mathrm{pH}$-stat strategy. $\mathrm{CPB}$ flow was maintained at $150 \mathrm{~mL} \cdot \mathrm{kg}^{-1} \cdot \mathrm{min}^{-1}$. During 90 minutes of DHCA, the esophageal temperature was kept at $18^{\circ} \mathrm{C}$ by means of a temperature-controlled blanket. The patent foramen ovale was closed through a right atriotomy. CPB was reinstituted, and the animals were rewarmed to achieve a rectal temperature of $38^{\circ} \mathrm{C}$ over 40 minutes. The 


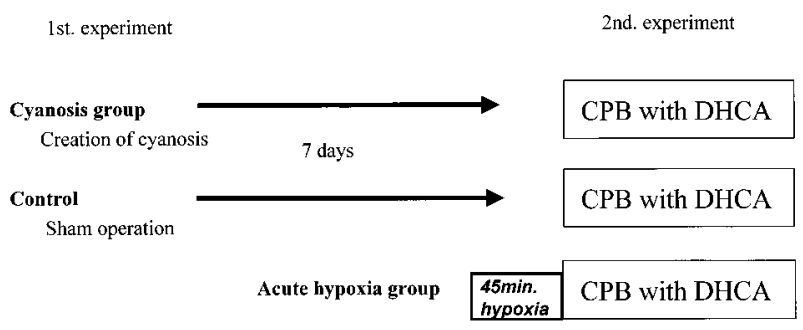

Fig 1. Experimental protocol.

heart was defibrillated as necessary at a temperature of $32^{\circ} \mathrm{C}$. The animals were then weaned from bypass and observed for 2 hours after reperfusion. The esophageal temperature was kept at $37^{\circ} \mathrm{C}$ after the termination of CPB. Sodium bicarbonate was added when the base excess exceeded $3.0 \mathrm{mmol} / \mathrm{L}$, and the hematocrit value was kept at $20 \%$ during CPB and between $23 \%$ and $25 \%$ after CPB. Electrolyte solution (Normosol-R) containing glucose $(5 \mathrm{~g} / \mathrm{L})$ and homologous blood were used for maintenance.

Data analysis. Pulmonary/systemic flow ratio (Qp/Qs) was estimated by the following formula:

$$
\mathrm{Qp} / \mathrm{Qs}=\left(\mathrm{Sat} \mathrm{O}_{2 \mathrm{AO}}-\mathrm{Sat} \mathrm{O}_{2 \mathrm{MV}}\right) /\left(\mathrm{Sat} \mathrm{O}_{2 \mathrm{PV}}-\mathrm{Sat} \mathrm{O}_{2 \mathrm{PA}}\right)
$$

where Sat $\mathrm{O}_{2}$ is oxygen saturation at various positions $(\mathrm{AO}=$ aorta, $\mathrm{MV}=$ mixed venous, and $\mathrm{PV}=$ pulmonary vein $)$, and it was assumed that oxygen saturation in the pulmonary vein was $100 \%$ on $100 \%$ oxygen and $98 \%$ on $21 \%$ oxygen. Cardiac index was calculated by the following equation:

(Ved - Ves) $\cdot$ Heart rate/Body surface area

where Ved is end-diastolic LV volume and Ves is end-systolic LV volume. Body surface area was calculated by the following formula ${ }^{7}$ :

$$
\text { Body surface area }\left(\mathrm{m}^{2}\right)=0.08 \cdot(\text { Body weight })^{2 / 3}
$$

Digitalized data were obtained at $300 \mathrm{~Hz}$ during the transient occlusion of the IVC for 10 seconds and stored in a computer. End-systole was defined as the point of maximal ratio of instantaneous LV pressure to LV volume. End-diastole was defined as the first point at which $\mathrm{dV} / \mathrm{dt}$ was 0 out of the points of an LV volume more than $80 \%$ of the maximum LV volume in each cardiac cycle.

LV volume was calculated by the following ellipsoidal model:

$$
\mathrm{LV} \text { volume }=(\pi / 6)\left(\mathrm{D}_{\mathrm{L}}\right)\left(\mathrm{D}_{\mathrm{S}}\right)^{2}
$$

where $D_{L}$ is long axis length and $D_{S}$ is short axis length obtained by ultrasonic transducers.

The first derivative of $\mathrm{LV}$ pressure $(\mathrm{dP} / \mathrm{dt})$ was calculated as a running 7-point method. Stroke work (SW) was calculated as the integral of $\mathrm{LV}$ pressure ( $\mathrm{LVp}$ ) and $\mathrm{LV}$ volume over each cardiac cycle by the following formula:

$$
\mathrm{SW}=\int \square \mathrm{LVp} \cdot \mathrm{dV}
$$

Preload recruitable stroke work (PRSW) is defined as the slope of the relation between stroke work (SW) and end-diastolic LV volume (Ved) by the following formula:

$$
\mathrm{SW}=\mathrm{PRSW} \cdot(\mathrm{Ved}-\mathrm{VW})
$$

where $\mathrm{Vw}$ is the intercept with the volume axis.

Tau is a time constant of isovolumic relaxation from the maximum negative $\mathrm{dP} / \mathrm{dt}$ to the timing of mitral valve opening and is defined as the inverse slope of linear regression line derived from the relation between natural log of LV pressure (in millimeters of mercury) and time (in milliseconds) by the following equation:

$$
\mathrm{P}=\mathrm{P}_{\mathrm{o}} \cdot \mathrm{e}^{-\mathrm{t} / \mathrm{T}}
$$

where $\mathrm{P}$ is $\mathrm{LV}$ pressure, $\mathrm{t}$ is time after the maximum negative $\mathrm{dP} / \mathrm{dt}$, and $\mathrm{P}_{0}$ is the pressure at the time of the maximum negative $\mathrm{dP} / \mathrm{dt}$.

In a preliminary study we found that PRSW and tau were dependent on heart rate (Fig 2). We derived curvilinear regression lines as a normal value from the average PRSW and tau of 10 neonatal lambs at each heart rate from 120 to 260 beats/min. PRSW and tau in this study were expressed by both absolute value and heart rate-normalized data (percentage of normal value).

Biochemistry. Serial plasma samples were taken from the coronary sinus line before $\mathrm{CPB} ; 5$ minutes after onset of $\mathrm{CPB}$; and after 5, 20, 60, and 120 minutes of reperfusion. LV tissue was collected from the free wall at the end of the experiment, immediately frozen in liquid nitrogen, and stored at $-70^{\circ} \mathrm{C}$ until analyzed. Total plasma concentrations of $\mathrm{NO}_{2}-$ and $\mathrm{NO}_{3}$-nitric oxide (NO) products in coronary sinus plasma were measured by the modified Griess reaction (nitrate/nitrite colorimetric assay kit; Cayman Chemical, Ann Arbor, Mich). Malondialdehyde and 4-hydroxyalkenals, the end products of the breakdown of polyunsaturated fatty acids during the process of lipid peroxidation, in the LV tissue and malondialdehyde in coronary sinus plasma were measured by the spectrophotometric method. In brief, LV tissue was homogenized in $20 \mu \mathrm{mol} / \mathrm{L}$ Tris- $\mathrm{HCl}$ buffer at $\mathrm{pH} 7.4$ and centrifuged. The supernatant was collected and assayed (LPO586; Calbiochem, San Diego, Calif). The myocardial antioxidant reserve capacity was assessed by the method of Godin and colleagues. ${ }^{8}$ In brief, homogenated heart tissue was incubated with several different concentrations of tbutylhydroperoxide in saline-azide $(0-8 \mathrm{mmol} / \mathrm{L})$ for $30 \mathrm{~min}$ utes at $37^{\circ} \mathrm{C}$. Reactions were terminated by sodium arsenite $(0.1 \mathrm{~mol} / \mathrm{L})$ in cold trichloroacetic acid $(28 \% \mathrm{wt} / \mathrm{vol})$. After centrifugation, the supernatant was mixed with thiobarbituric acid solution $(0.5 \%$ in sodium hydroxide, $0.025 \mathrm{~mol} / \mathrm{L})$ and boiled for 15 minutes. The formation of thiobarbituric acid-reactive substances was assessed by the absorbance at $532 \mathrm{~nm}$.

Epinephrine was measured in arterial plasma at baseline and at 1 hour of reperfusion.

Animals in this study received humane care in compliance with the "Principles of Laboratory Animal Care" formulated 


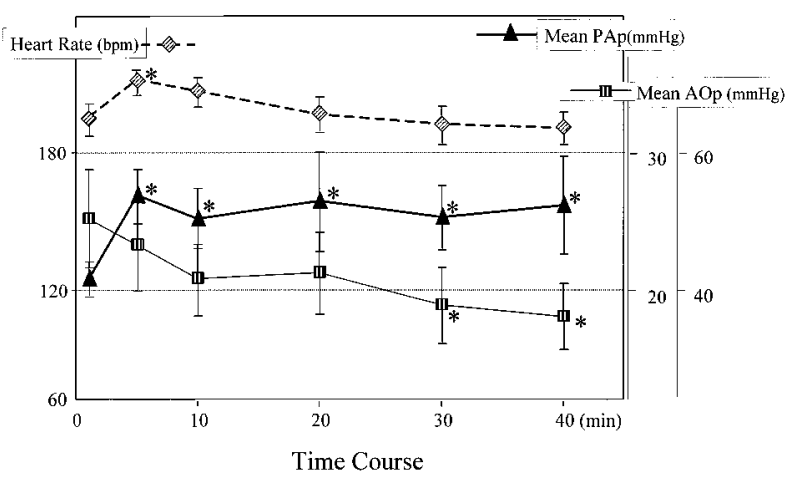

Fig 2. Hemodynamics, including heart rate, mean arterial pressure $(A O p)$, and mean pulmonary pressure $(P A p)$, during 40 minutes of hypoxic ventilation in the AH group. $* P<.05$ compared with value at the beginning of hypoxic ventilation.

by the National Society for Medical Research and "Guide for the Care and Use of Laboratory Animals" prepared by the National Academy of Sciences and published by the National Institutes of Health (National Institutes of Health publication No. 86-23, revised in 1985).

Statistics. All values are expressed as means \pm SEM. Data were compared by use of the 2-tailed unpaired Student $t$ test or repeated-measures analysis of variance.

\section{Results}

Validation of cyanosis and baseline measurements. Baseline measurements were performed for validation of cyanosis and acute hypoxia (Table I). The cyanosis model produced a consistent and significantly lower $\mathrm{PaO}_{2}$ and Qp/Qs at an $\mathrm{FIO}_{2}$ of $21 \%$. At an $\mathrm{FIO}_{2}$ of $100 \%, \mathrm{Qp} / \mathrm{Qs}$ and $\mathrm{PaO}_{2}$ significantly increased compared with values at an $\mathrm{FIO}_{2}$ of $21 \%$ in the cyanotic animals. Acute increase in arterial oxygen resulted in significantly improved LV function (Table I).

Hemodynamics during acute hypoxic stress. Acute hypoxic ventilation resulted in significant hypoxemia (Table I), pulmonary hypertension, tachycardia, and systemic hypotension despite volume adjustment (Fig 3).

Hemodynamics after CPB and cardiac performance. One animal in each group required a very small amount of isoproterenol (INN: isoprenaline; 2-4 $\mu \mathrm{g} / \mathrm{kg}$ ) at weaning from CPB because of bradycardia caused by pulmonary hypertension. Therefore, no inotropic agents were used. Two animals died of severe cardiac dysfunction in the AH group at 90 and 110 minutes after CPB before completion of the experiments.

Postischemic cardiac index was significantly lower in the $\mathrm{AH}$ group than in the other 2 groups, and there was

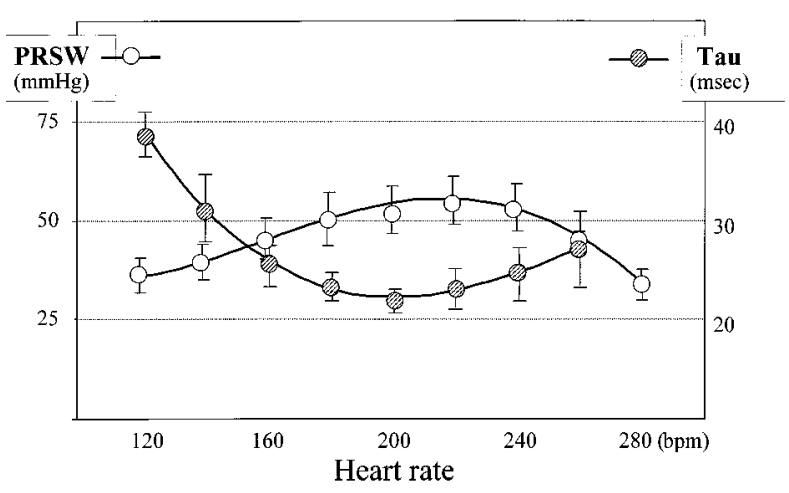

Fig 3. Relationship between PRSW or tau and heart rate in normal neonatal lambs. Baseline heart rates in the neonatal lambs are 160 to 200 beats/min under the same anesthetic methods as this study. Heart rate was changed by right atrial pacing (heart rate $>160$ beats $/ \mathrm{min}$ ) or topical cooling of the sinus node with atrial pacing (heart rate $<160$ beats/min). PRSW and tau have a peak around heart rates of 180 to 220 beats/min.

a tendency toward a lower heart rate at 2 hours of reperfusion in the $\mathrm{AH}$ group $(P=.07)$ than in the other groups. The recovery of PRSW (Fig 4) and tau (Fig 5) at 2 hours of reperfusion was significantly worse in the $\mathrm{AH}$ group than the others. PRSW at 2 hours of reperfusion was slightly but significantly worse in the cyanosis group than in the control group.

NO metabolites. NO metabolites significantly increased in the early period of reperfusion and reached normal levels by 60 minutes of reperfusion in both the cyanosis and control groups. However, in the AH group NO metabolite levels did not increase in the early period of reperfusion and were significantly decreased at 120 minutes of reperfusion. This level was significantly lower than that found in the cyanosis and control groups (Fig 6).

Coronary sinus malondialdehyde, myocardial lipid peroxidation, and antioxidant reserve capacity. Malondialdehyde levels in the coronary sinus were significantly higher in the early reperfusion period than 5 minutes after the start of CPB in each of the groups (Fig 7). The level of malondialdehyde did not increase with institution of CPB in any groups, although CPB did result in abrupt reoxygenation in the cyanosis group and the $\mathrm{AH}$ group. In addition, there were no significant differences in malondialdehyde levels in the coronary sinus among groups at any time. There were no significant differences in 4-hydroxyalkenals and malondialdehyde levels in the myocardial tissue at 2 hours of reperfusion among groups (Fig 8). There were also no significant differences in myocardial antioxi- 
Table I. Baseline measurements and validation of cyanosis and acute alveolar hypoxia

\begin{tabular}{|c|c|c|c|c|c|c|}
\hline \multirow[b]{2}{*}{ Variables $\mathrm{FIO}_{2}$} & \multicolumn{2}{|c|}{ Cyanosis } & \multicolumn{2}{|c|}{ Control } & \multicolumn{2}{|c|}{ Acute hypoxia } \\
\hline & $21 \%$ & $100 \%$ & $21 \%$ & $100 \%$ & $10 \%$ & $100 \%$ \\
\hline $\mathrm{PaO}_{2}(\mathrm{~mm} \mathrm{Hg})$ & $35.0 \pm 2.7^{* \ddagger}$ & $79.6 \pm 12.5$ & $92.5 \pm 7.4$ & $516.9 \pm 29.3$ & $28.6 \pm 6.4^{* \rightleftarrows}$ & $489.3 \pm 32.3$ \\
\hline Saturated $\mathrm{O}_{2}(\%)$ & $70.6 \pm 3.5^{* \neq}$ & $93.6 \pm 2.3$ & $97.0 \pm 1.0$ & $100.0 \pm 0.0$ & $62.3 \pm 8.9^{* \neq}$ & $100 \pm 0.0$ \\
\hline $\mathrm{Qp} / \mathrm{Qs}$ & $0.57 \pm 0.06^{* \neq}$ & $0.83 \pm 0.05$ & & & & \\
\hline \multicolumn{7}{|l|}{ Cardiac function } \\
\hline PRSW (mm Hg) & $36.9 \pm 3.8^{\dagger \neq}$ & $56.1 \pm 3.3$ & $58.6 \pm 4.8$ & $62.6 \pm 5.0$ & $33.0 \pm 4.3^{\dagger+}$ & $56.1 \pm 2.6$ \\
\hline Tau (ms) & $30.4 \pm 2.7^{\dagger}$ & $25.1 \pm 2.4$ & $25.1 \pm 2.9$ & $26.3 \pm 3.1$ & $31.6 \pm 3.8^{\dagger \ddagger}$ & $23.6 \pm 0.9$ \\
\hline
\end{tabular}

Values are means \pm SEM

$* P<.005$ compared with value at $100 \%$ oxygen within each group

$\dagger P<.05$ compared with value at $100 \%$ oxygen within each group.

$\ddagger P<.05$ compared with control.

dant reserve capacity at any concentrations of t-butylhydroperoxide (Fig 9).

Catecholamine. Acute hypoxia significantly increased arterial plasma epinephrine, and its level in the AH group was significantly higher than that at $21 \%$ oxygen in the cyanosis group (Fig 10).

\section{Discussion}

The present study has demonstrated that the recovery of chronically cyanotic neonatal hearts after DHCA was only marginally worse than that of normoxemic hearts. However, acute alveolar hypoxic stress before CPB resulted in significantly worse recovery of both systolic and diastolic cardiac function. The mechanism of injury in the $\mathrm{AH}$ group may relate to an impairment of NO production. There was no evidence that oxygenderived free radicals are related to any of the differences among cyanotic, acyanotic, and acutely hypoxic animals in recovery of LV function after ischemia.

There have been conflicting reports on the effects of chronic cyanosis on the vulnerability to ischemic injury. In several studies chronic alveolar hypoxia increases the tolerance to ischemia in immature hearts. ${ }^{1,2}$ Baker and colleagues ${ }^{1}$ demonstrated that 7 to 10 days of alveolar hypoxia beginning at birth was associated with less ventricular dysfunction after ischemia in immature isolated rabbit hearts. In contrast, Nakanishi and collaegues ${ }^{9}$ showed that chronic alveolar hypoxia decreased postischemic cardiac output in isolated rat hearts. However, chronic alveolar hypoxia induces pulmonary vasoconstriction and pulmonary hypertension with right ventricular hypertrophy, and these effects may exert an influence on cardiac function and susceptibility to an ischemic insult. Fujiwara and colleagues ${ }^{3}$ created a neonatal cyanosis model by creating a similar left PA-LA shunt and reported that chronically cyanotic neonatal hearts had a significantly worse ventricular functional recovery than normoxemic hearts after 2 hours of hypothermic arrest in the isolated heart model. Silverman and colleagues ${ }^{10}$ also created a cyanosis model with a PA-LA shunt and distal PA banding in adult dogs. They demonstrated that after a period of global ischemia, the cyanosis group had a significant depression of ventricular function associated with a reduction of adenosine triphopshate and high phosphate creatine levels in the LV tissue. The results of the current study are consistent with the results reported in Fujiwara and Silverman's studies. However, the recovery of cardiac function after DHCA in the cyanotic animals was marginally (but significantly strategically) worse than that found in the normoxemic animals in this study. In addition, we could not find any differences in biochemical data, lipid peroxidation, and NO metabolites between cyanotic and acyanotic hearts.

Other investigators have used a model with acute (12 hours) hypoxic stress before CPB as a cyanosis model. ${ }^{4-6}$ This acute alveolar model has been reported to be associated with severe myocardial dysfunction after ischemia. ${ }^{4}$ The current study also showed serious ventricular dysfunction after ischemia in the acute alveolar hypoxia group, which underwent a short duration of hypoxia at higher arterial oxygen levels $(30 \mathrm{~mm}$ $\mathrm{Hg}$ of $\mathrm{PaO}_{2}$ ) of hypoxia than in the previous reports. We initially attempted to maintain hypoxia for 2 hours and $\mathrm{a} \mathrm{PaO}_{2}$ of $25 \mathrm{~mm} \mathrm{Hg}$, but no animals tolerated this level of acute hypoxic stress. Acute hypoxia induced pulmonary hypertension, increased heart rate, and ultimately resulted in severe systemic hypotension despite intravascular volume expansion. For these reasons, we chose a $\mathrm{PaO}_{2}$ of $30 \mathrm{~mm} \mathrm{Hg}$.

Hypoxia is reported to activate glycolysis to shift metabolism from an oxidative pattern to a glycolytic pattern. ${ }^{11}$ Acute hypoxia has been demonstrated to 

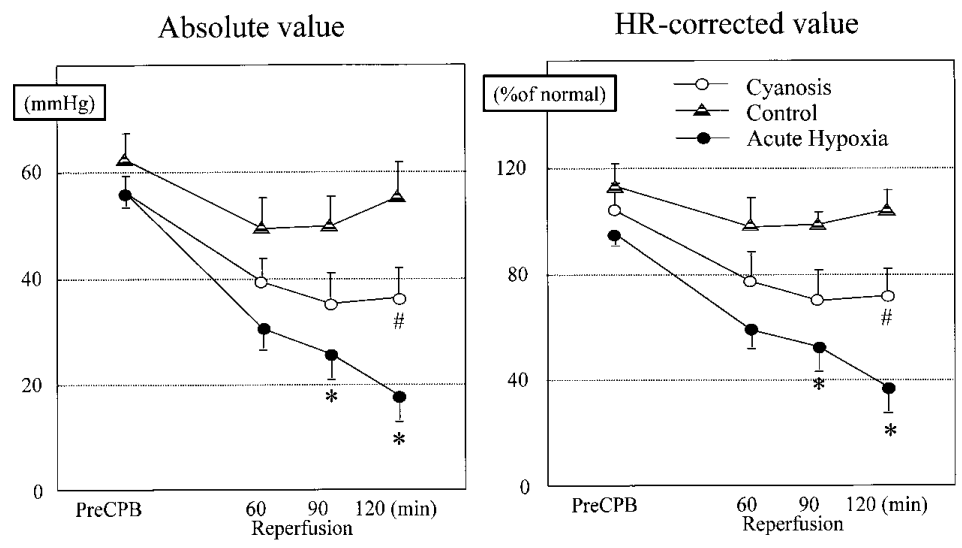

Fig 4. Preload recruitable stroke work before and after CPB. Left panel shows absolute values, and right panel shows value corrected for heart rate and expressed as percentage of normal values. $* P<.05$ compared with control and cyanosis. $\# P<.05$ compared with control.
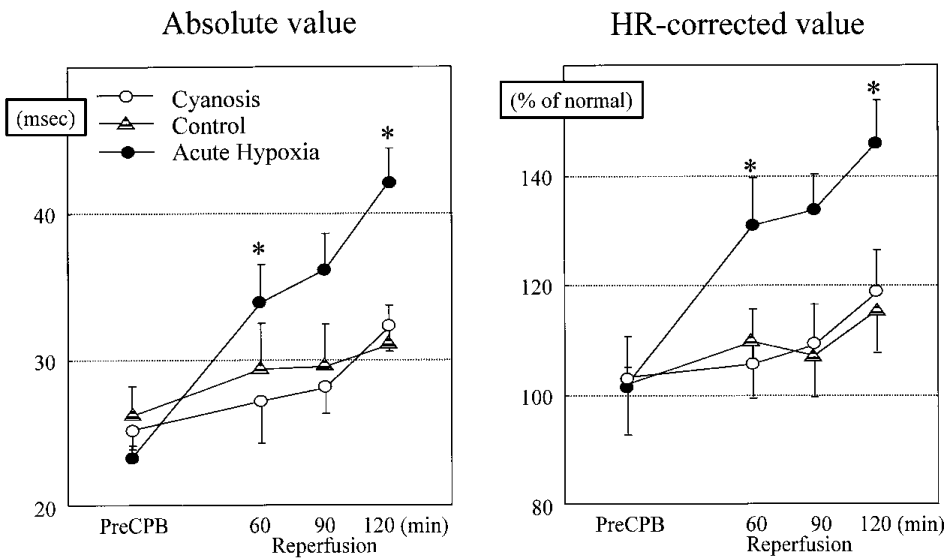

Fig 5. Tau, time constant of isovolumic relaxation, before and after CPB. Left panel shows absolute values, and right panel shows values corrected by heart rate and expressed as percentage of normal value. $* P<.05$ compared with control and cyanosis.

decrease myocardial glycogen, adenosine triphosphate, and ventricular function in isolated rat hearts. ${ }^{12}$ Conversely, myocardial adenosine triphosphate content measured by magnetic resonance spectroscopy is not depleted in cyanotic patients. ${ }^{13}$ In addition, a deterioration of hemodynamics caused by acute hypoxia resulted in an increase in plasma catecholamine levels in the current study. Higher catecholamine levels may increase myocardial oxygen consumption and may accelerate consumption of myocardial energy sources during hypoxia. Subsequent ischemia-reperfusion could then exaggerate the depletion of energy stores. Bolling and colleagues ${ }^{6}$ reported that the adenosine triphosphate/diphosphate ratio was significantly reduced after ischemia in a model of acute hypoxic stress, and Shimada and colleagues ${ }^{14}$ have noted that high concentrations of epinephrine before ischemia caused heart dysfunction after ischemia. Capsi and colleagues ${ }^{15}$ observed similar findings that administration of epinephrine before ischemia reduced postischemic recovery of ventricular function in immature piglets. In our study chronic cyanosis did not increase the level of epinephrine before CPB.

Ihnken and colleagues ${ }^{5}$ showed that acute alveolar hypoxic stress before $\mathrm{CPB}$ caused an increase in the generation of oxygen-derived free radicals after the onset of $\mathrm{CPB}$, and myocardial antioxidant reserve capacity was reduced in neonatal animals. In addition, 


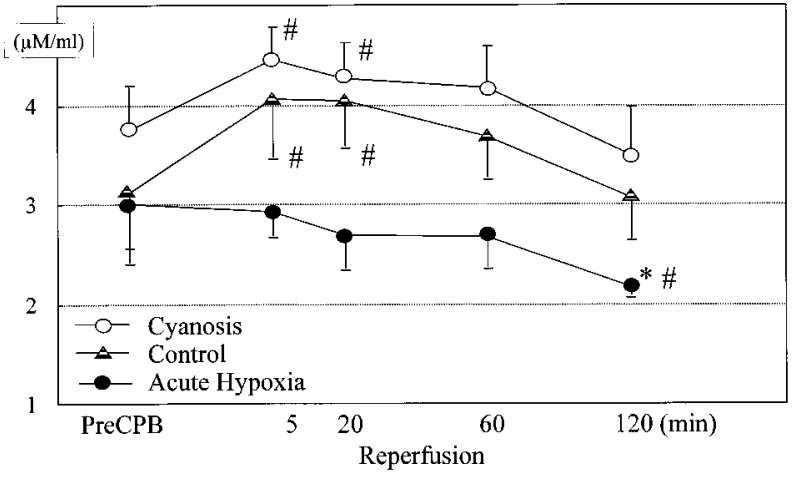

Fig 6. Nitric oxide metabolites in the coronary sinus plasma before and after CPB. ${ }^{*} P<.05$ compared with control and cyanosis. $\# P<.05$ compared with the value at baseline with each group.

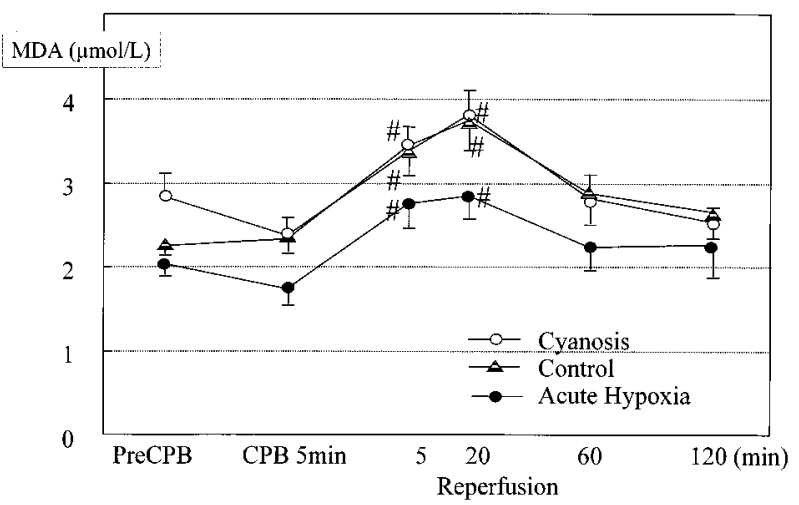

Fig 7. Malondiadehyde in the coronary sinus plasma before and after $C P B$. $\# P<.05$ compared with the value at 5 minutes after onset of $\mathrm{CPB}$ with each group.

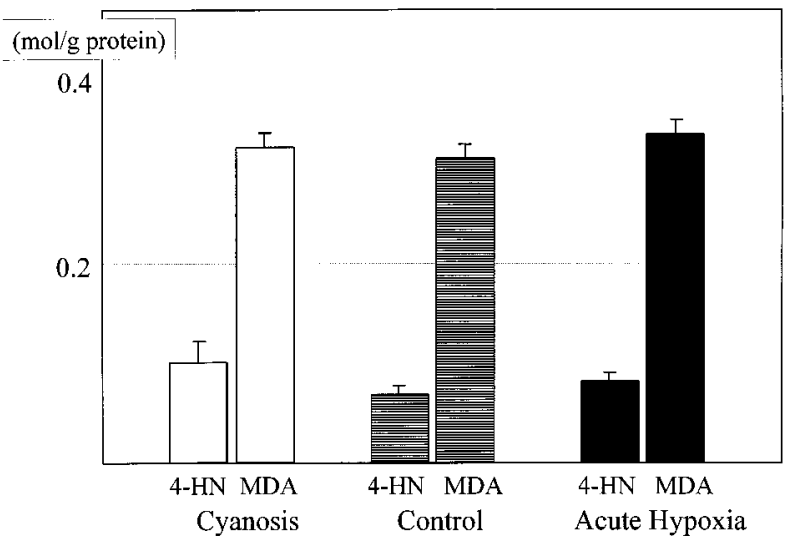

Fig 8. Myocardial lipid peroxidation at 2 hours of perfusion. 4-HN, 4-Hydroxyalkenals; $M D A$, malondialdehyde.

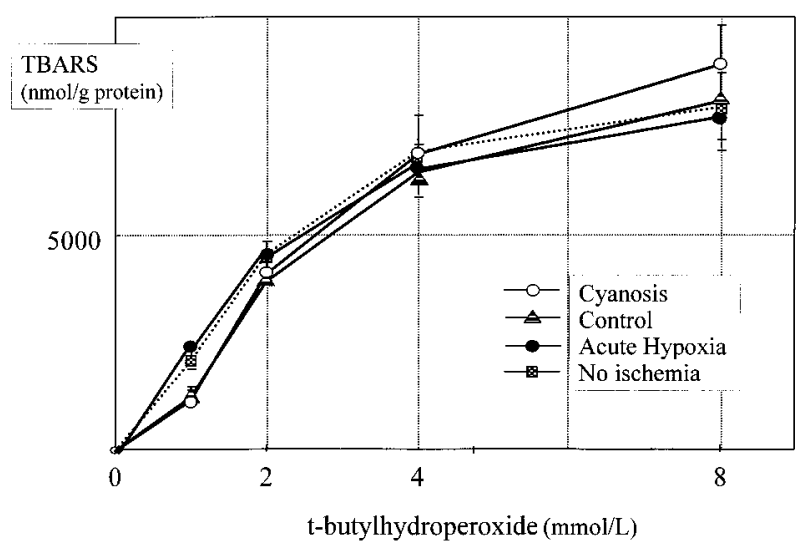

Fig 9. Myocardial antioxidant reserve capacity at 2 hours of reperfusion. Dotted line shows antioxidant reserve capacity of LV tissue after 5 hours of $100 \%$ oxygen ventilation but without ischemia.

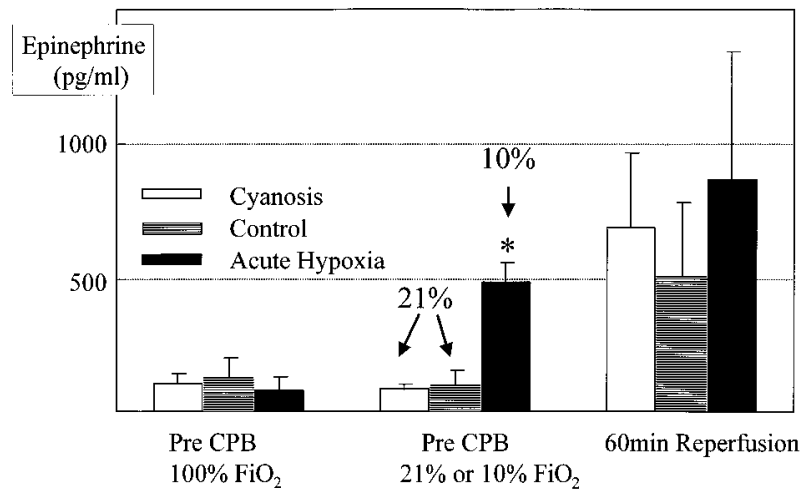

Fig 10. Arterial epinephrine level before and after CPB. $* P<.05$ compared with control and cyanosis.

they demonstrated that hypoxemia-reoxygenation was associated with higher levels of lipid peroxidation products and less myocardial antioxidant capacity than normothermic global ischemia-reperfusion. In our studies institution of CPB did not increase the level of lipid peroxidation products in the cyanosis group or the AH group despite abrupt reoxygenation. However, the level of malondialdehyde significantly increased in the early reperfusion period in all 3 groups. In contrast with the results of Ihnken and colleagues, our findings suggested that ischemia-reperfusion caused more production of free radicals than hypoxemia-reoxygenation. We did not find differences in the level of malondialdehyde in the coronary sinus after ischemia or in either lipid peroxidation or antioxidant reserve capaci- 
ty in myocardial tissue at 2 hours of reperfusion among the 3 groups. The mechanism by which free radicals decrease antioxidant reserve capacity in tissue is unclear, although free radicals cause protein degradation. In the tissues, the antioxidant system is composed of both enzymatic and nonenzymatic defenses. The antioxidant enzymatic system consists of catalase, superoxide dismutase, and glutathione peroxidase, and the most abundant nonenzymatic scavengers are vitamin $\mathrm{E}$, vitamin $\mathrm{C}$, and glutathione. In the clinical setting, many investigators have reported that antioxidant enzymatic activities are either increased or unchanged after reperfusion. ${ }^{16-18}$ Teoh and colleagues ${ }^{16}$ reported that these 3 enzymatic activities in cyanotic patients and in those with coronary artery bypass graft procedures were not different before and after ischemia. Kim and colleagues ${ }^{17}$ reported that myocardial catalase, superoxide dismutase, and glutathione peroxidase significantly increased after reperfusion in patients with tetralogy of Fallot. Aceto and colleagues ${ }^{18}$ also demonstrated an increase in glutathione peroxidase activity from the right atrium of patients undergoing heart operations at reperfusion. Our finding that myocardial antioxidant reserve capacity of the 3 groups after DHCA was not different from that of nonischemic hearts is in agreement with the results of the study by Teoh and colleagues. ${ }^{16}$

Another potentially important finding in this study was that postischemic NO production was different in the chronic cyanosis and $\mathrm{AH}$ groups. The $\mathrm{AH}$ group had lower levels of NO metabolites in the coronary sinus after ischemia. It has been reported that ischemiareperfusion causes an impairment of the coronary arterial response to endothelium-dependent vasodilation. ${ }^{19}$ This endothelial dysfunction may reduce production of NO after ischemia, resulting in a limitation of coronary arterial flow and cardiac dysfunction. We hypothesize that acute hypoxia before ischemia-reperfusion may have exaggerated postischemic endothelial dysfunction, although we did not assess coronary endothelial function in this study.

Several experimental cyanosis models have been reported: a PA-LA shunt, ${ }^{3,10,20}$ an IVC-LA shunt, ${ }^{21,22}$ and PA banding with atrial septal defect creation. ${ }^{23} \mathrm{We}$ chose the LA-PA shunt for this study because PA banding with atrial septal defect produces a high right ventricular pressure, and the IVC-LA shunt decreases the right ventricular volume, which could affect the geometry of the left ventricle and render the assumption of an ellipsoidal model for the LV volume calculation invalid.

In conclusion, chronic cyanosis without alveolar hypoxia augments the susceptibility to ischemia to some extent. In contrast, acute hypoxic stress was associated with severe postischemic ventricular dysfunction. Acute hypoxic stress also caused an impairment of postischemic NO production, which was not observed in the animals with chronic cyanosis. Free radical injury does not appear to explain the differences in recovery of cardiac function after ischemia among cyanotic, acyanotic, and acutely hypoxic neonatal animals. Therefore, the acute hypoxic stress model may not be applicable in understanding the effects of ischemia-reperfusion in the clinical setting of cyanotic congenital heart disease.

We thank Susan Boissonneault for assistance in the preparation of the manuscript.

\section{REFERENCES}

1. Baker JE, Curry BD, Olinger GN, Gross JG. Increased tolerance of the chronically hypoxic immature heart to ischemia: contribution of $\mathrm{K}_{\text {ATP }}$ channel. Circulation 1997;95:1278-85.

2. Tajima M, Katayose D, Bessho M, Isoyama S. Acute ischaemic preconditioning and chronic hypoxia independently increase myocardial tolerance to ischemia. Cardiovasc Res 1994;28:3129.

3. Fujiwara T, Kurtts T, Anderson W, Heinle J, Mayer JE Jr. Myocardial protection in cyanotic neonatal lambs. J Thorac Cardiovasc Surg 1988;96:700-10.

4. Ihnken K, Morita K, Buckberg GD, Matheis G, Sherman MP, Allen BS, et al. Studies of hypoxemic/reoxygenation injury: without aortic clamping. II. Evidence for reoxygenation damage. J Thorac Cardiovasc Surg 1995;110:1171-81.

5. Ihnken K, Morita K, Buckberg GD, Sherman MP, Young HH. Studies of hypoxemic/reoxygenation injury: without aortic clamping. III. Comparison of the magnitude of damage by hypoxemia/reoxygenation versus ischemia/reperfusion. J Thorac Cardiovasc Surg 1995;110:1182-9.

6. Bolling K, Kronon M, Allen BS, Wang T, Ramon S, Feinberg H. Myocardial protection in normal and hypoxically stressed neonatal hearts: the superiority of blood versus crystalloid cardioplegia. J Thorac Cardiovasc Surg 1997;113:994-1005.

7. Hawk CT, Leary SL. Formulary for laboratory animals. Ames: Iowa State University Press; 1995. p. 78.

8. Godin DV, Ko KM, Garnet ME. Altered antioxidant status in the ischemic/reperfused rabbit myocardium: effects of allopurinol. Can J Cardiol 1989;5:365-71.

9. Nakajima K, Inoue M, Sugawara E, Sano S. Ischemic and reperfusion injury of cyanotic myocardium in chronic hypoxic rat model: changes in cyanotic myocardial antioxidant system. J Thorac Cardiovasc Surg 1997;114:1088-96.

10. Silverman NA, Kohler J, Levitsky S, Pavel DG, Fang RB, Feinberg H. Chronic hypoxemia depresses global ventricular function and predisposes to the depletion of high-energy phosphates during cardioplegic arrest: implications for surgical repair of cyanotic congenital heart defects. Ann Thorac Surg 1984;34:304-9.

11. Robin ED, Murphy BJ, Theodore J. Coordinate regulation of glycolysis by hypoxia in mammalian cells. J Cell Physiol 1984;118:287-90. 
12. Merati G, Alliobardi S, Monti LD, de Jong JW, Samaja M. Dynamics of myocardial adaptation to low-flow ischemia and hypoxemia. Am J Physiol 1996;271:H2300-5.

13. Miall-Allen VM, Kemp GJ, Rajagopalan B, Taylor DJ, Radda GK, Haworth SG. Magnetic resonance spectroscopy in congenital heart disease. Heart 1996;75:614-9.

14. Shimada Y, Yamamoto F, Yamamoto H, Oka T. Effect of preischemic catecholamine treatment on ischemia-reperfusion injury of the myocardium: subtype, dose and temperature dependency. Jpn Circ J 1998;62:517-26.

15. Caspi J, Coles JG, Benson LN, Herman SL, Augustine J, Tsao P, et al. Effects of high plasma epinephrine and $\mathrm{Ca}^{2+}$ concentration on neonatal myocardial function after ischemia. $\mathrm{J}$ Thorac Cardiovasc Surg 1993;105:59-67.

16. Teoh KH, Mickle DAG, Weisel RD, Li R, Tumiati LC, Coles JG, et al. Effect of oxygen tension and cardiovascular operations on myocardial antioxidant enzyme activities in patients with tetralogy of Fallot and aorta-coronary bypass. J Thorac Cardiovasc Surg 1992;104:159-64.

17. Kim KB, Chung HH, Kim MS, Rho JR. Changes in the antioxidative defensive system during open heart operations in humans. Ann Thorac Surg 1994;58:170-5.

18. Aceto A, Mezzeti A, Di Ilio C, Calafiore AM, De Cesare D, Bosco G, et al. Effect of ischemia-reperfusion on glutathione peroxidase, glutathione reductase and glutathione transferase activities in human heart protected by hypothermic cardioplegia. Free Radic Res Commun 1990;8:85-91.

19. Nakanishi K, Vinten-Johansen J, Lefer DJ, Zhao Z, Fowler WC, McGee S, et al. Intracoronary 1-arginine during reperfusion improves endothelial function and reduces infarct size. Am J Physiol 1992;263:H1650-8.

20. Warner KG, Quinn CC, Klein RD, Connolly RJ. Use of an adjustable tourniquet to reverse cyanosis in the newborn pig. Ann Thorac Surg 1997;63:456-8.

21. Barragry TP, Blatchford JW, Tuna IC, Lillehei TJ, Ring WS. Left ventricular dysfunction in a canine model of chronic cyanosis. Surgery 1987;10:362-70.

22. Pridjian AK, Bove EL, Lupinetti FM. The effects of cyanosis on myocardial blood flow, oxygen utilization, and lactate production in dogs. J Thorac Cardiovasc Surg 1995;109:849-53.

23. Bernstein D, Voss E, Huang S, Doshi R, Crane C. Differential regulation of right and left ventricular $\beta$-adrenergic receptors in newborn lambs with experimental cyanotic heart disease. J Clin Invest 1990;85:68-74.

\section{Discussion}

Dr Verdi J. DiSesa (Chicago, Ill). Why did you include a group with acute cyanosis? Were the $\mathrm{PO}_{2}$ values in the $\mathrm{AH}$ group the same as those found in the chronic cyanosis group?

Dr Nagashima. I tried to keep a $\mathrm{PO}_{2}$ of $30 \mathrm{~mm} \mathrm{Hg}$ and an absolute $\mathrm{PO}_{2}$ of $28.6 \mathrm{~mm} \mathrm{Hg}$ during hypoxic ventilation. Therefore, there was a little bit lower arterial oxygen value in the AH group.

Dr DiSesa. Are you saying that the insult was more severe in the AH group?

Dr Nagashima. That is right.

Dr DiSesa. Did you see compensatory changes in the more chronic cyanotic group? Did they get hyperemic or polycythemic?

Dr Nagashima. The animals were cyanotic for only 7 days. Hematocrit value increased a little bit, but it was not significantly different between the control and cyanotic animals.

\section{THE THORACIC SURGERY FOUNDATION FOR RESEARCH AND EDUCATION}

\section{Harvard Executive Course}

The next offering of the Harvard Executive Course, Understanding the New World of Health Care, will be November 11-19, 2000. Applications from Harvard can be obtained by contacting Eleanor Brimley at 617-4961069. Alley-Sheridan Scholarship materials are available from The Foundation. Please contact Lainie Castle at 312-644-6610, extension 4798.

\section{0-2001 Research Award Applications}

Information and applications for 2000-2001 Thoracic Surgery Foundation Research Grants, Research Fellowships, and Career Development Awards are now available. Please contact Lainie Castle at 312-644-6610 (telephone), 312-527-6635 (fax), or lcastle@sba.com (E-mail). 